\title{
Crafting a Response in Times of Tragedy
}

\author{
Rev Dr Russell Briese \\ Coordinator, Pastoral Care \\ Griffith University
}

\begin{abstract}
When it happens a tragedy, especially of an international nature, will touch the lives of students and staff in an educational institution whose members represent a larger diversity than the local society. This paper reflects on the process Griffith University Chaplaincy followed in responding to two international events in 2019, namely the Christchurch mosque attacks and the Sri Lankan bombings. It identifies, within the process followed, two main aspects, namely identifying appropriate students as a reference group and working with the university as a whole. It concludes with a quick guide for those called on to respond at times of tragedy.
\end{abstract}

\section{Keywords}

university, chaplaincy, pastoral care, tragedy, international

\section{Introduction}

This paper is a reflection on the processes we followed at Griffith University in response to two specific events in 2019. It is offered in the hope that it may enable others, who may feel called to respond or who are asked to respond to such events, a real sense of being poised for action.

Sometimes events in our world stop us in our tracks.

Locally, a student death by accident, or a suicide on campus, grabs the attention of a university more used to aspiration than grief.

Internationally, a plane crash, natural disaster in a foreign land, or surges of war and terrorism touch an institution whose members represent a large diversity of society as a whole.

The year 2019 proved no exception to trauma and tragedy. In our part of the world it was no longer business as usual after the senseless execution of 50 innocent Muslims who gathered to pray in mosques in Christchurch in March. It was the worst atrocity in New Zealand's history, a targeted attack on a minority group.

Only a few weeks later, a second tragedy, the Easter Sunday bombings in Sri Lanka, had an even larger mortality rate. While not so close to home, and not affecting as many of our university community, the ripples of that tragedy were nonetheless felt on our campus.

In this paper, I am going to reflect on the process Griffith University Chaplaincy ${ }^{1}$ followed in responding to these two international events, helping the university community to appropriately mark the events and thereby providing and enabling pastoral care and attention to those who were grieving and whose lives were touched in the face of such violence.

While each case has different circumstances and impacts on different cohorts in different ways, a reflection on the processes followed can start to build a guide to help campus communities appropriately mark such occasions.

\section{Identify/contact appropriate students as reference group}

The first question to ask is: 'Who does this tragedy affect?'

While our thoughts might go to those New Zealanders amongst us, and those of Kiwi heritage, it was also clear there was a strong religious element in the attacks. The Muslim community was under

\footnotetext{
${ }^{1}$ Please note that from the end of 2019, Griffith University Chaplaincy is called Pastoral Care.
} 
attack, in their places of worship.

In the matter of the Christchurch tragedy, I contacted by email the president and vice-president of Griffith University Muslim Students Association (GUMSA). I expressed my condolence and offered to help them in any way they might find helpful. I suggested it might be useful to meet the following week to consider if they wished to mark the event in any way. We did in fact meet early in the new week. Such a face-to-face meeting is a good way to assess the general prevailing mood. In doing so, it ensures that any potential event is student-driven and will in fact be relevant and appropriate to the situation.

Being student-driven is an important principle. It is easy to do things for people, by offering what we think might be a nice gesture, but it is only by meeting and carefully listening that we offer that which may well extend beyond something 'nice' and facilitate a response which is both helpful and appropriate.

Furthermore, as is common in times of shock and grief, the response of those affected does not remain static, so a continued contact over a number of days will ensure a response which is appropriate and timely. Indeed in this case, the students' feeling was not to move to do anything too quickly. We 'hastened slowly,' giving students a time to move beyond 'raw' response, allowing time for the events and our response to be processed.

Following the same process in the aftermath of the Sri Lankan bombings, the first thing was to seek an appropriate contact partner, allowing the specific circumstances to speak.

In this case, Griffith University has no Sri Lankan student club. However, it is standard practice in case of disaster in a specific country that an email is sent out from the International Office to students studying at Griffith from the country in question, in this case Sri Lanka. Such emails characteristically express condolence and also point students to areas in the university where they can expect to find assistance, typically International Student Advisors, Counsellors, and Chaplains.

The lack of a specific student club representing affected students meant we had to employ alternative avenues to connect with students. Of course, it should be noted that if it proves impossible to engage a small group of students eager to work on a specific event, that is a signal that the energy is not present and is a sign that an event may not be appropriate. This is also a possible outcome.

Students who had presented to Counselling, Chaplaincy/Pastoral Care, or International Office staff for personal support were invited by the staff to contact me directly if they were interested to work with others on forming an event. They spoke to friends and acquaintances, and a couple of students identified their interest. I then wrote a letter to Sri Lankan students through the International Office asking them to contact a nominated student if they would be interested to engage on this issue.

In this instance it became clear that we were speaking to two separate cohorts, both international and domestic: students directly from Sri Lanka, as well as students who were from Sri Lankan background but Australian citizens.

Listening to these representative students, with Christchurch front of mind, I explained what had happened in that instance, namely gathering for a dinner. The students were however of the mind that a dinner felt more like a celebration, and from their cultural perspective they sought a more low key event. This was important advice to heed.

\section{Work with the university as a whole}

While close contact with appropriate student representatives is essential, to stage an event for and within the university, close collaboration with university officials is also required. It is essentially a two-pronged response.

Here it is simply a matter of working up the line of command. Once student partners were identified, 
I alerted university officials that I had had initial discussions with students, who seemed keen to mark the event in an appropriate way. The idea was thought by university officials to have merit, and so the process continued.

In this process the priorities of the university became clear. We were given some very specific advice. Continued consultation with the marketing and communications team ensured the university was fully on board. This meant any promotion of the event would be done in consultation with them, ensuring a unified and straightforward message. We were in turn advised that any event was to be multi-faith in nature. This promoted inclusivity for all, no matter what their religion. I was to be the master of ceremonies and ensure the event and speakers were all on message.

In the same way, in the case of responding to the Sri Lankan attacks, university officials, together with the marketing and communications team, were consulted in order to move forward in a way deemed appropriate and in congruence with university values and expectations.

\section{Caveat}

On occasion it may be that the student and university goals are at odds with one another. This will require some diplomacy and care. While individuals make up a university community, such events are corporate in nature, and the good of the whole institution is the final goal. International politics, where one country may be pitted against another, could also present real challenges for this process.

\section{Clarify the goal}

The above processes crystallised our goal in holding the event. We defined a clear goal for Christchurch as being 'An internal Griffith University event allowing our community to show solidarity with the families and friends of victims in the recent events in Christchurch, and showing Griffith University's commitment to respect, diversity and inclusion.'

I think the three key words were internal, solidarity and commitment. It was not a public event, but for people in the university community. It was meant to bring the university community together. It sought to foster assurance to all that they are part of a safe community. The higher profile the event takes, the more important it is to have clear goals.

\section{The outcome}

Just over 100 Griffith University students and staff attended a dinner remembering Christchurch almost two weeks after the event. The main speaker was an Imam from a local mosque, with a response by Christian and Jewish religious leaders. All outside speakers need to be vetted or trusted individuals. A speech from a university official underlined Griffith University's embrace of diversity and religious freedom. I assisted in providing notes for the speech, which noted Chaplaincy's involvement in Harmony Week and production of the Celebrating Cultural Diversity calendar. All who attended were able to come together in a spirit of unity and goodwill. The president of GUMSA closed the evening. GUMSA had made contact with other student clubs on campus, specifically religious ones, and it was heartening to see their representatives present on the evening. This ensured a participatory event, as far as possible.

The Sri Lankan commemoration was more modest in nature. The students set up a table in a central area of the Nathan campus of the university. It was adorned with cultural artefacts and symbols. A canvas was set up and people were invited to write messages of support. Again it was internal, held in the midst of the campus, and allowed passersby to show solidarity with those affected, and heralded a sense of commitment to be a place of safety and welcome.

\section{Ritual}

In order to be participatory, something 'hands on' is needed, a chance for all to participate appropriately. As people gather, they appreciate the chance to 'do something.' While lighting 
candles is often a popular ritual for many occasions, the use of candles is not widespread in Islamic tradition, so we avoided this in the case of the Christchurch event. We did use candles for Sri Lanka, since most of those targeted were Christian. In both cases a tangible participatory opportunity was a canvas, on which people were invited to write messages as they saw fit. The canvases have been hung in Student Services and International offices with a small descriptor. Of course food is always a great thing to bring people together, and this can be more or less elaborate according to budget.

\section{Conclusion}

With the above case studies in mind, we are now ready to detail a guide to help us in times of tragedy to appropriately mark such occasions. With this guide at hand, those called on at such times will not need to reinvent the wheel. The guide is purposely not onerous or of major detail, but simply some basic information which points the way. My suggestion is to file the guide somewhere that others can find it and pick it up and work from. Everything should not depend on one person.

This paper is a reflection on the processes we followed at Griffith University in response to two specific events in 2019. It is offered in the hope that it can assist those given such tasks in a real sense be poised for action. It is written from the perspective of Chaplaincy and Pastoral Care. This is a service many universities have to offer pastoral care for individuals and for the institution as a whole. It may well be however that other support staff could facilitate such events, e.g. International Student Advisors, Counsellors, or other student advisors.

A crucial role, opportunity, is to bring people together, mark the events appropriately, and give hope for the future. 


\section{A Quick Guide for Those Called on to Respond at Times of Tragedy}

To be filed where individuals who may be charged with such tasks can easily find it and adapt to the circumstances

Step one:

- Identify/contact an appropriate contact partner, ensuring any event is student-driven and will be relevant and appropriate to the situation.

- $\quad$ Continued contact with student stakeholders over a number of days will help to monitor the feeling and mood of the students.

- $\quad$ Please note that If it proves impossible to engage a small group of students eager to work on a specific event, an event may not be appropriate.

- Students may be identified by consulting students clubs (e.g. religious or cultural groups), or those who present to Counselling, Chaplaincy/Pastoral Care, or International Student Advisors for personal support. Great care must be taken especially in the later areas with regards to individual privacy.

- Note stakeholders may span more than one homogenous group (e.g. international and domestic).

Step two:

- Work with the university as a whole. Once a working group of students is established and engaged, contact should be made to university officials, including marketing and communication staff to ensure a unified approach in congruence with university goals and values. This contact also ensures the event embraces the university community and not just the affected cohort.

Goals:

- The goals of any event are broadly that they are be internal, promote solidarity with those affected, and commitment to inclusion.

Ritual:

- Consider which participatory 'hands on' activities might be appropriate to engage those who gather. E.g. lighting candles, writing messages on a canvas on in a condolence book 


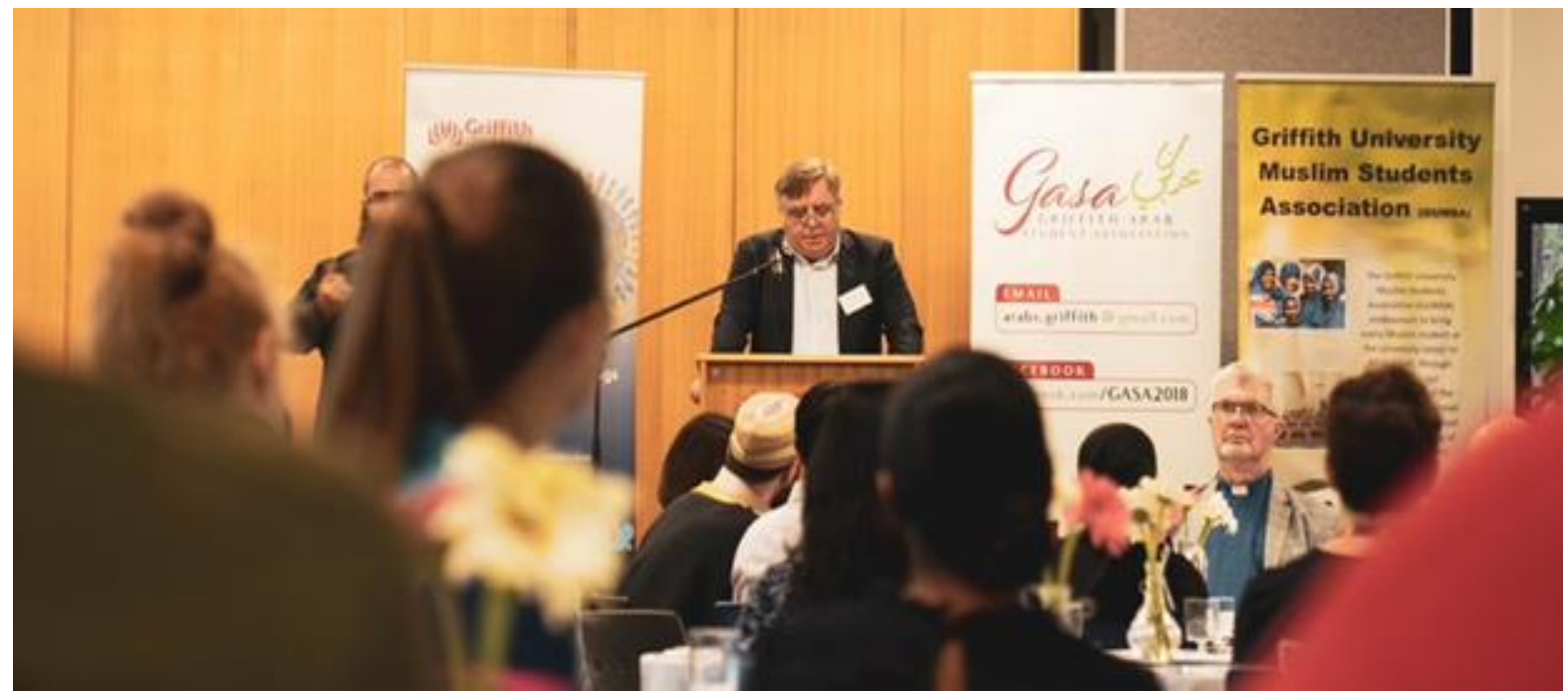

The author, Dr Russell Briese, leads the evening in response to the Christchurch massacre.

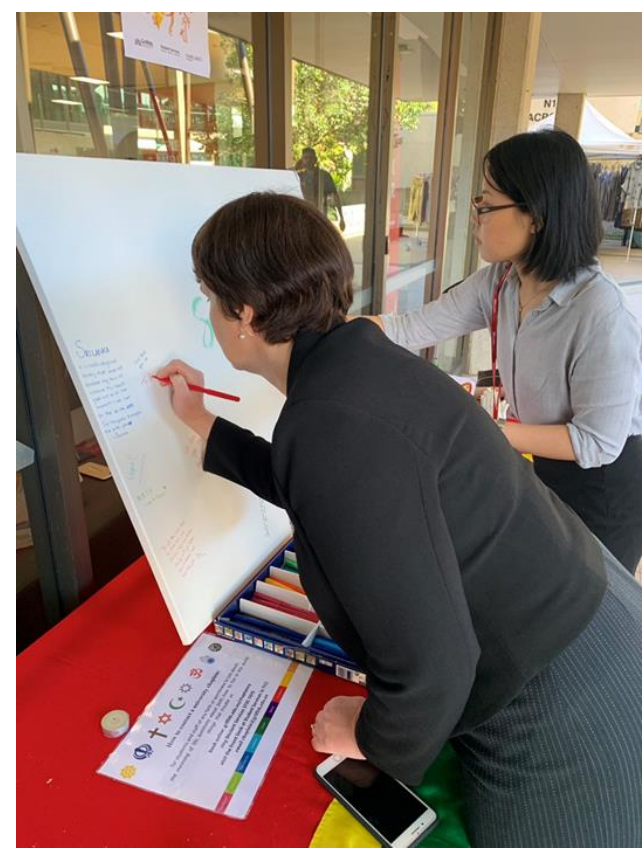

Griffith University Vice-Chancellor and President, Professor Carolyn Evans writes a message of support for Sri Lanka.

The author may be contacted:

r.briese@griffith.edu.au

\section{Please cite this paper as:}

Briese, R. (2020). Crafting a response in times of tragedy. Journal of the Australian and New Zealand Student Services Association, 28(1), 34-39. https:Ildoi.org.10.30688/janzssa.2019.01 